\title{
Original Article \\ Characteristics of Seawater and Sediment in Coastal Areas of Ninh Thuan
}

\author{
Pham Huu Tam* \\ Sub-Institute of Hydro Meteorology and Climate Change (SIHYMECC - IMHEN) \\ 19 Nguyen Thi Minh Khai, 1 District, Ho Chi Minh City, Vietnam \\ Received 26 July 2018 \\ Revised 05 November 2018; Accepted 14 December 2018
}

\begin{abstract}
This paper represents some aspects of the environmental quality of coastal areas in Ninh Thuan province. Results of two surveys (performed in July 2013, and February 2014) showed that in the water environment, Dissolved Oxygen- DO values were relatively high (always \&gt;5mg/l). Values of Total Suspended Solids - TSS, nutrients amoni, nitrite, nitrate, phosphate, silicate and heavy metals $\mathrm{Pb}, \mathrm{Hg}$, As were in the narrow ranges and always were lower than acceptable values for aquatic life protection. In general, values of nutrients amoni, nitrite, nitrate và phosphate were usually lower in Nha Trang bay but higher in the coastal area of Phu Yen. In July 2013, values of TSS, nutrients nitrate, silicate were higher than those in February 2014, while $\mathrm{Hg}$ was contrary.

In sediment, concentrations of organic Carbon were suitable for benthos. Concentrations of Phosphorus and Nitrogen in samples were not high so it does not affect aquatic life. In general, the quality of the sediment in Ninh Hai was better than that of the Ninh Phuoc. Concentrations of Phosphorus and Nitrogen in sediment were higher in February 2014.

Keywords: Coastal seawater quality, sediment quality, nutrients, heavy metal, south central, Ninh Thuan.
\end{abstract}

\footnotetext{
"Corresponding author.

E-mail address: tamphamhuu@gmail.com

https://doi.org/10.25073/2588-1094/vnuees.4273
} 


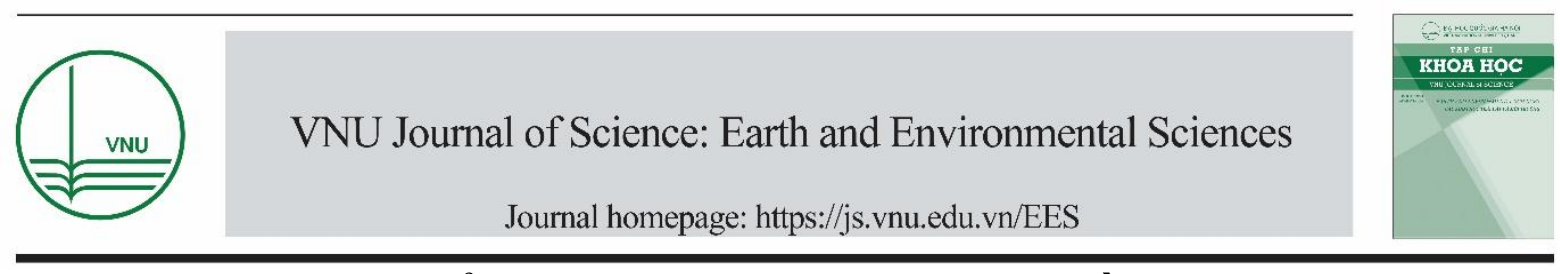

\title{
Đặc điểm môi trường nước và trầm tích vùng biển ven bờ Ninh Thuận
}

\author{
Phạm Hữu Tâm* \\ Phân viện Khoa học Khí tuợng Thủy văn và Biến đổi khi hậu (SIHYMECC), \\ Số 19 Nguyễn Thị Minh Khai, Quận 1, TP. Hồ Chí Minh, Việt Nam \\ Nhận ngày 26 tháng 7 năm 2018 \\ Chỉnh sửa ngày 05 tháng 11 năm 2018; Chấp nhận đăng ngày 14 tháng 12 năm 2018
}

Tóm tắt: Bài báo trình bày kết quả khảo sát chất lượng môi trường khu vực biển ven bờ Ninh Thuận. Kết quả phân tích qua hai chuyến khảo sát tháng 7/2013 và tháng 2/2014 cho thấy môi trường nước có hàm lượng ôxy hòa tan $(\mathrm{DO})$ tương đối cao (luôn $>5 \mathrm{mg} / \mathrm{l})$. Hàm lượng tổng chất rắn lơ lửng (TSS), muối dinh dưỡng amoni, nitrit, nitrat, phosphat, silicat và các kim loại nặng $\mathrm{Pb}, \mathrm{Hg}, \mathrm{As}$ biến động trong phạm vi hẹp, luôn thấp hơn giá trị giới hạn (GTGH) đối với nước nuôi trồng thủy sản, bảo tồn thủy sinh. Nhìn chung, hàm lượng các muối dinh dưỡng amoni, nitrit, nitrat và phosphat đều thấp hơn so với vịnh Nha Trang, nhưng lại cao hơn so với vùng biển ven bờ Phú Yên. Vào tháng 7/2013hàm lượng của TSS, muối dinh dưỡng nitrat, silicat thường cao hơn so với tháng 2/2014, trong khi đó $\mathrm{Hg}$ có xu thế ngược lại.

Trong môi trường trầm tích, hàm lượng carbon hữu cơ phù hợp cho đời sống động vật đáy, hàm lượngN và $\mathrm{P}$ không cao nên không gây ảnh hưởng xấu cho đời sống thủy sinh. Nhìn chung, chất lượng môi trường trầm tích tại khu vực Ninh Hải tốt hơn so với khu vực Ninh Phước. Hàm lượng nitơ hữu cơ và photpho tổng số trong trầm tích thường cao hơn vào tháng 2/2014.

Tù khóa: Chất lượng nước biển ven bờ, chất lượng trầm tích, muối dinh dưỡng, kim loại nặng, Nam trung bộ, Ninh Thuận.

\section{Mở đầu}

Vùng biển ven bờ Ninh Thuận, trong đó có hai khu vực nghiên cứu thuộc Ninh Phước và Ninh Hải chịu ảnh hưởng của hiệu ứng nước trồi, có tính đa dạng và phong phú về tài nguyên sinh vật biển với năng suất sinh học cao, được đặc trưng bởi các rạn san hô, thảm cỏ

\footnotetext{
Tác giả liên hệ.

Địa chỉ email: tamphamhuu@gmail.com
}

https://doi.org/10.25073/2588-1094/vnuees.4273 biển, sinh vật đáy và các nguồn lợi thuỷ sản phong phú khác [1]. Đây là hai vị trí mà Chính phủ dự định xây dựng hai nhà máy điện hạt nhân đầu tiên tại Việt Nam. Những năm gần đây Viện Hải dương học đã chủ trì nhiều đề tài nghiên cứu về các điều kiện hải dương học, môi trường, sinh thái, sinh học tại vùng biển Ninh Thuận, như chương trình "Xây dựng chương trình giám sát định kỳ rạn san hô tại Ninh Thuận" thực hiện từ năm 2006 -2011, trong khuôn khổ chương trình giám sát và bảo vệ các khu Bảo tồn Biển Việt Nam [2]. Hàng năm, Sở $\mathrm{TN}$ và $\mathrm{MT}$ tỉnh Ninh Thuận đều có chương 
trình quan trắc môi trường biển ven bờ. Tù̀ 2001-2006, Liên đoàn Địa chất Biển (MGMC) đã tiến hành đề tài: "Điều tra địa chất, khoáng sản, địa chất môi trường và tai biến địa chất vùng biển Nam Trung Bộ tỷ lệ $1 / 100.000$ và một số vùng trọng điểm tỷ lệ $1 / 50.000 "$, diện tích điều tra $9.700 \mathrm{~km}^{2}$ thuộc vùng biển từ Tuy Hoà đến Vũng Tàu... Tuy nhiên, cho đến nay, các dẫn liệu điều tra nghiên cứu, khảo sát về điều kiện môi trường tại hai khu vực nghiên cứu hầu như chưa có các tài liệu điều tra cơ bản cũng như các số liệu về môi trường (chương trình quan trắc nước biển ven bờ hàng năm của Sở TN và MT Ninh Thuận chỉ tập trung tại các cảng cá, các khu du lịch và vùng nuôi trồng thủy sản [3]) hoặc dữ liệu về môi trường đã lạc hậu, chưa cập nhật (đề tài "Điều tra địa chất, khoáng sản, địa chất môi trường và tai biến địa chất vùng biển Nam Trung Bộ tỷ lệ $1 / 100.000$ và một số vùng trọng điểm tỷ lệ $1 / 50.000 "$ đã tiến hành cách đây hơn 12 năm [4]).

Vì vậy, việc tiến hành điều tra, khảo sát để cập nhật dữ liệu về môi trường, tạo phông nền về các thông số môi trường, đánh giá hiện trạng chất lượng môi trường cũng như hiểu rõ đặc điểm môi trường nước và trầm tích ở vùng biển ven bờ Ninh Thuận nói chung và hai khu vực biển ven bờ (nơi dự định xây dựng hai nhà máy điện hạt nhân đầu tiên của Việt Nam) riêng là cần thiết. Nhằm giúp các nhà quản lý định hướng và đưa ra các giải pháp hữu hiệu nhằm bảo vệ môi trường vùng biển ven bờ vùng nghiên cứu.

\section{Tài liệu và phương pháp nghiên cứu}

\subsection{Thông tin về vị trí trạm và khu vực nghiên cúu}

Cả hai khu vực biển ven bờ thuộc xã Phước Dinh, huyện Ninh Phước và xã Vĩnh Hải, huyện Ninh Hải được khảo sát qua ba mặt cắt với chín trạm mặt rộng. Tuy nhiên, các thông số môi trường tại Ninh Phước chỉ thu tại 7 trạm (gồm trạm $1,2,4,5,6,7$ và 8 ) và tại Ninh Hải chỉ thu tại 6 trạm (gồm trạm 10,11,13,14, 15 và 16 ). Hai chuyến khảo sát đã được tiến hành vào tháng 7/2013 và tháng $2 / 2014$, có tổng cộng 52 mẫu nước biển và 19 mẫu trầm tích biển được thu và phân tích. Mẫu nước được thu tại tầng mặt và đáy có độ sâu từ 10-65 mét, mẫu trầm tích được thu tại lớp $5 \mathrm{~cm}$ bề mặt. Vùng biển nghiên cứu quanh năm sóng to gió lớn (động lực mạnh) và hầu như không có hệ thống sông ngòi đổ ra biển. Vị trí trạm thu mẩu được trình bày trong hình 1 .

\subsection{Phwơng pháp thu, phân tích và xử lý số liệu}

Các thông số môi trường trong nước biển bao gồm ôxy hòa tan (DO), tổng chất rắn lơ lửng (TSS), các muối dinh dưỡng amoni, nitrit, nitrat, phosphat, silicat, các kim loại nặng $\mathrm{Pb}$, $\mathrm{Hg}$, As và trong mẫu trầm tích gồm carbon hữu cơ $(\mathrm{Chc})$, nitơhữu cơ $(\mathrm{Nhc})$ và phospho tổng số (Pts) đã được lựa chọn để nghiên cứu và được phân tích tại phòng thí nghiệm trọng điểm Quốc gia thuộc Viện Hải dương học. Các mẫu nước biển và trầm tích biển được xử lý, bảo quản và phân tích theo các phương pháp hiện hành nêu trong các tiêu chuẩn Việt Nam (cho $\mathrm{DO}$ và TSS); Standard Methods for Examination of Water and Wastewater - APHA, 2012 (cho các muối dinh dưỡng và kim loại nặng trong nước biển ven bờ) và các phương pháp phân tích, quan trắc môi trường nước và trầm tích của Tổ chức Lương nông Thế giới - FAO, 1975 (cho các thông số trong mẫu trầm tích biển) $[5,6]$. Ôxy hòa tan sử dụng phương pháp Winkler. TSS phân tích bằng phương pháp trọng lượng. Amoni được phân tích bằng phương pháp xanh indophenol. Nitrit được phân tích phương pháp trắc quang phức màu hồng của nitrit với $\alpha$ naphthylamine và acid sulfanilic. Nitrat được khử thành nitrit qua cột khử $\mathrm{Cd}$ mạ đồng và phân tích theo cùng phương pháp. Phosphat và silicat được phân tích bằng phương pháp xanh molybden. Các kim loại nặng, trước tiên được xử lý bằng hỗn hợp dung dịch acid đậm đặc $\left(\mathrm{HNO}_{3}+\mathrm{H}_{2} \mathrm{SO}_{4}\right)$, sau đó đem phân tích trên máy quang phổ phát xạ ICP-MS.Mẫu trầm tích trước khi phân tích sẽ được sấy khô ở nhiệt độ $105^{\circ} \mathrm{C}$. C hữu cơ xác định bằng cách cho mẫu trầm tích tác dụng với hỗn hợp Sulfochromic và lượng $\mathrm{K}_{2} \mathrm{Cr}_{2} \mathrm{O}_{7}$ thừa được phân định bằng muối Mohr. $\mathrm{N}$ hữu cơ được phân tích bằng phương pháp Kiejdahn. $\mathrm{P}$ tồng số được phân tích bằng phương pháp xanh molybden sau khi được phá mẫu bằng hỗn hợp acid đậm đặc $\left(\mathrm{HNO}_{3}+\mathrm{H}_{2} \mathrm{SO}_{4}\right)$. 


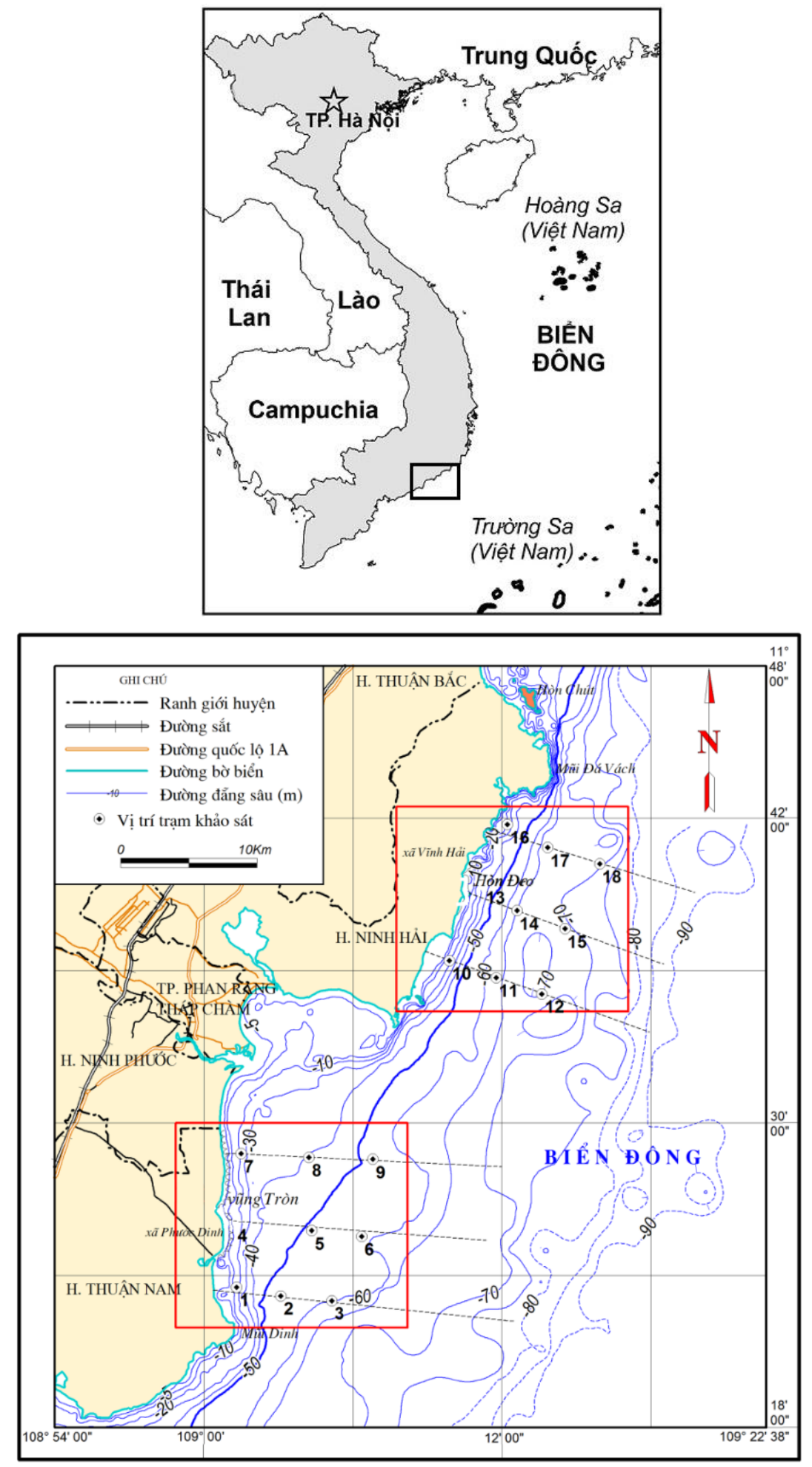

Hình 1. Vị trí các trạm nghiên cứu. 
Chất lượng nước biển được đánh giá dựa trên Quy chuẩn Kỹ thuật Quốc gia về chất lượng nước biển ven bờ (các trạm nghiên cứu đều nằm cách bờ trong phạm vi 3 hải lí) - áp dụng cho vùng nuôi trồng thủy sản bảo tồn thủy sinh (QCVN 10-MT:2015/BTNMT) [7]. Các thông số nitrit, nitrat không quy định trong QCVN 10-MT:2015/BTNMT thì sử dụng Tiêu chuẩn chất lượng nước thủy sản của các nước ASEAN [8]. Các hình ảnh đồ thị trong bài báo được tạo bằng phần mềm Microsoft Excel.

\section{Kết quả nghiên cứu}

\subsection{Hiện trạng môi trường nước biển ven bờ}

Bảng 1. Giá trị thống kê các muối dinh dưỡng trong nước

\begin{tabular}{|c|c|c|c|c|c|c|c|}
\hline \multirow{2}{*}{ Thời gian } & \multirow{2}{*}{ Vị trí } & \multirow{2}{*}{ Giá trị } & \multirow{2}{*}{$\frac{\mathrm{NH}_{3,4}-\mathrm{N}}{(\mu \mathrm{g} / \mathrm{l})}$} & \multirow{2}{*}{$\frac{\mathrm{NO}_{2}-\mathrm{N}}{(\mu \mathrm{g} / \mathrm{l})}$} & \multirow{2}{*}{$\frac{\mathrm{NO}_{3}-\mathrm{N}}{(\mu \mathrm{g} / \mathrm{l})}$} & \multirow{2}{*}{$\frac{\mathrm{PO}_{4}-\mathrm{P}}{(\mu \mathrm{g} / \mathrm{l})}$} & \multirow{2}{*}{$\frac{\mathrm{SiO}_{3}-\mathrm{Si}}{(\mu \mathrm{g} / \mathrm{l})}$} \\
\hline & & & & & & & \\
\hline \multirow{8}{*}{$\begin{array}{l}\text { Tháng } \\
\text { 7/2013 }\end{array}$} & \multirow{4}{*}{$\begin{array}{l}\text { Khu vực ven bờ Ninh } \\
\text { Phước } \\
\text { (Ninh Thuận I) }\end{array}$} & $\mathrm{TB}$ & 6,8 & 0,7 & 32 & 10,2 & 164 \\
\hline & & $\mathrm{LN}$ & 22,0 & 6,0 & 34 & 15,8 & 275 \\
\hline & & $\mathrm{BN}$ & KPH & KPH & 28 & 6,8 & 90 \\
\hline & & $n$ & 14 & 14 & 14 & 14 & 14 \\
\hline & \multirow{4}{*}{$\begin{array}{l}\text { Khu vực ven bờ Ninh } \\
\text { Hải } \\
\text { (Ninh Thuận II) }\end{array}$} & ТВ & 5,2 & 0,5 & 30 & 10,1 & 144 \\
\hline & & $\mathrm{LN}$ & 16,0 & 2,2 & 31 & 13,0 & 285 \\
\hline & & $\mathrm{BN}$ & KPH & $\mathrm{KPH}$ & 28 & 7,1 & 46 \\
\hline & & $n$ & 12 & 12 & 12 & 12 & 12 \\
\hline \multirow{8}{*}{$\begin{array}{l}\text { Tháng } \\
\text { 2/2014 }\end{array}$} & \multirow{4}{*}{$\begin{array}{l}\text { Khu vực ven bờ Ninh } \\
\text { Phước } \\
\text { (Ninh Thuận I) }\end{array}$} & $\mathrm{TB}$ & 7,0 & 4,6 & 30 & 10,3 & 106 \\
\hline & & $\mathrm{LN}$ & 23,0 & 12,0 & 33 & 12,0 & 136 \\
\hline & & $\mathrm{BN}$ & $\mathrm{KPH}$ & 1,6 & 27 & 9,1 & 75,0 \\
\hline & & $n$ & 14 & 14 & 14 & 14 & 14 \\
\hline & \multirow{4}{*}{$\begin{array}{l}\text { Khu vực ven bờ Ninh } \\
\text { Hải } \\
\text { (Ninh Thuận II) }\end{array}$} & $\mathrm{TB}$ & 3,7 & 4,8 & 29 & 9,6 & 86 \\
\hline & & $\mathrm{LN}$ & 16,0 & 10,0 & 31 & 10,7 & 107 \\
\hline & & $\mathrm{BN}$ & KPH & 2,0 & 26 & 8,4 & 67 \\
\hline & & $n$ & 12 & 12 & 12 & 12 & 12 \\
\hline
\end{tabular}

Ghi chú: TB: trung bình; BN: bé nhất; LN: lớn nhất; n: số mẫu; KPH: không phát hiện.
Kết quả xử lý dữ liệu được trình bày trong các bảng 1,2 và hình 2,3 cho thấy tại hai khu vực nghiên cứu trong cả hai đợt khảo sát hàm lượng DO luôn $>5 \mathrm{mg} / \mathrm{l}$, hầu hết giá trị hàm lượng của các thông số trong môi trường nước đều thấp, sự phân bố của các yếu tố môi trường là khá đồng nhất, ít có sự dao động về giá trị. Các thông số môi trường nước như TSS, các muối dinh dưỡng nitrit, nitrat, phosphatcó giá trị biến đổi trong phạm vi rất hẹp. Hàm lượng của amoni và silicat có dao động, nhưng không đáng kể, hàm lượng cao của hai yếu tố này thường tập trung ở các trạm gần bờ. Hàm lượng của các kim loại nặng $\mathrm{Pb}, \mathrm{Hg}$, As luôn bé và phạm vi dao động tương đối hẹp. 
Bảng 2. Giá trị thống kê của ôxy hòa tan, tổng chất rắn lơ lửng và các kim loại nặng trong nước

\begin{tabular}{|c|c|c|c|c|c|c|c|}
\hline \multirow{2}{*}{ Thời gian } & \multirow{2}{*}{ Vị trí } & \multirow{2}{*}{ Giá trị } & DO & TSS & $\mathrm{Pb}$ & $\mathrm{Hg}$ & As \\
\hline & & & $(\mathrm{mg} / \mathrm{l})$ & $(\mathrm{mg} / \mathrm{l})$ & $(\mu \mathrm{g} / \mathrm{l})$ & $(\mu \mathrm{g} / \mathrm{l})$ & $(\mu \mathrm{g} / \mathrm{l})$ \\
\hline \multirow{8}{*}{ Tháng 7/2013 } & \multirow{4}{*}{$\begin{array}{l}\text { Khu vực ven bờ Ninh } \\
\text { Phước } \\
\text { (Ninh Thuận I) }\end{array}$} & TB & 6,93 & 2,93 & 1,61 & 0,19 & 2,76 \\
\hline & & $\mathrm{LN}$ & 7,16 & 9,95 & 1,92 & 0,28 & 3,75 \\
\hline & & $\mathrm{BN}$ & 6,62 & 1,08 & 1,33 & 0,18 & 1,79 \\
\hline & & $n$ & 7 & 7 & 5 & 5 & 5 \\
\hline & \multirow{4}{*}{$\begin{array}{l}\text { Khu vực ven bờ Ninh } \\
\text { Hải } \\
\text { (Ninh Thuận II) }\end{array}$} & TB & 7,14 & 3,08 & 2,01 & 0,17 & 2,86 \\
\hline & & $\mathrm{LN}$ & 7,31 & 6,62 & 3,64 & 0,22 & 4,55 \\
\hline & & $\mathrm{BN}$ & 6,88 & 1,43 & 1,13 & 0,09 & 2,14 \\
\hline & & $n$ & 6 & 6 & 5 & 5 & 5 \\
\hline \multirow{8}{*}{ Tháng 2/2014 } & \multirow{4}{*}{$\begin{array}{l}\text { Khu vực ven bờ Ninh } \\
\text { Phước } \\
\text { (Ninh Thuận I) }\end{array}$} & TB & 7,07 & 2,14 & 1,72 & 0,02 & 3,15 \\
\hline & & $\mathrm{LN}$ & 7,22 & 3,73 & 2,71 & 0,03 & 4,30 \\
\hline & & $\mathrm{BN}$ & 6,72 & 1,32 & 1,09 & 0,01 & 2,00 \\
\hline & & $n$ & 7 & 7 & 5 & 5 & 5 \\
\hline & \multirow{4}{*}{$\begin{array}{l}\text { Khu vực ven bờ Ninh } \\
\text { Hải } \\
\text { (Ninh Thuận II) }\end{array}$} & TB & 7,17 & 1,44 & 2,05 & 0,02 & 1,94 \\
\hline & & $\mathrm{LN}$ & 7,28 & 1,73 & 2,94 & 0,03 & 2,50 \\
\hline & & $\mathrm{BN}$ & 6,78 & 1,16 & 1,34 & 0,02 & 1,30 \\
\hline & & $n$ & 6 & 6 & 5 & 5 & 5 \\
\hline
\end{tabular}

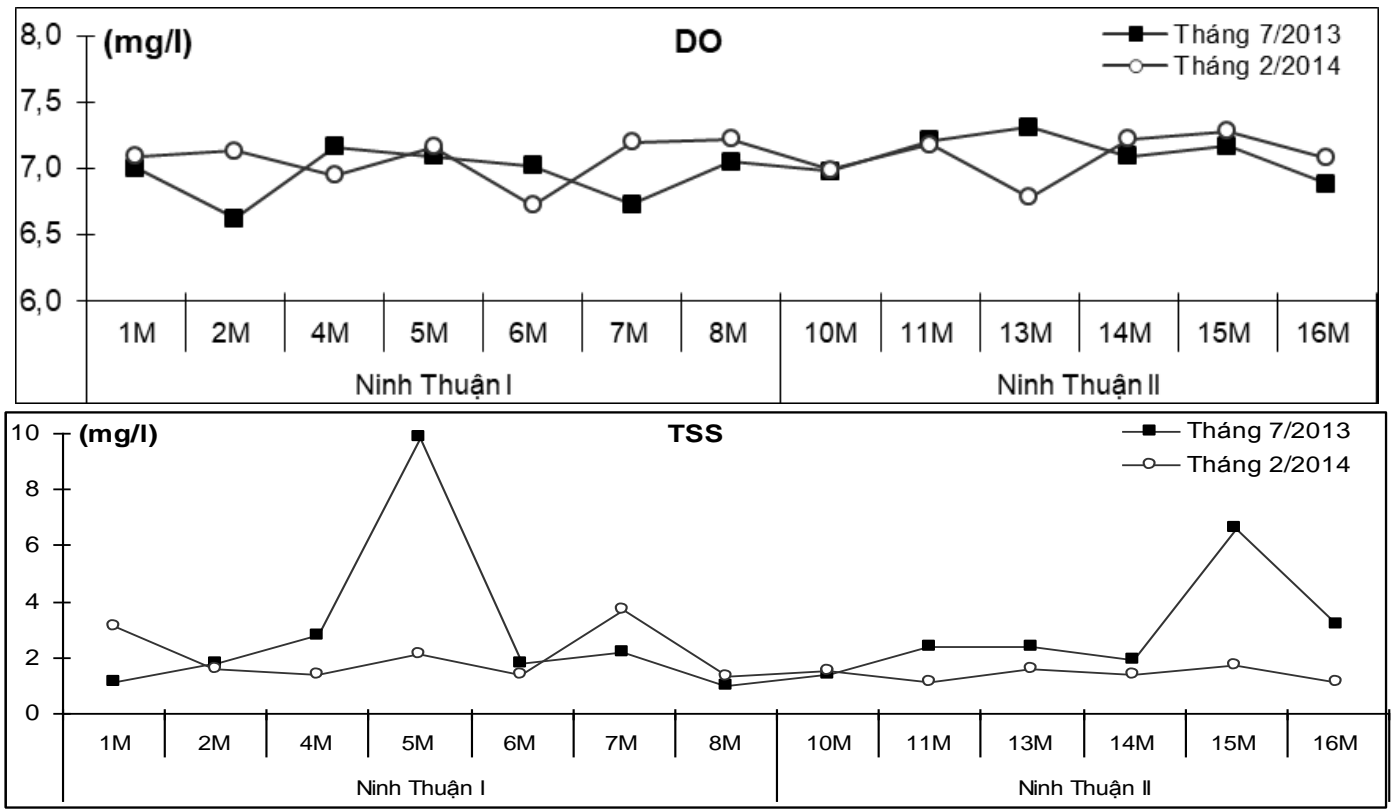



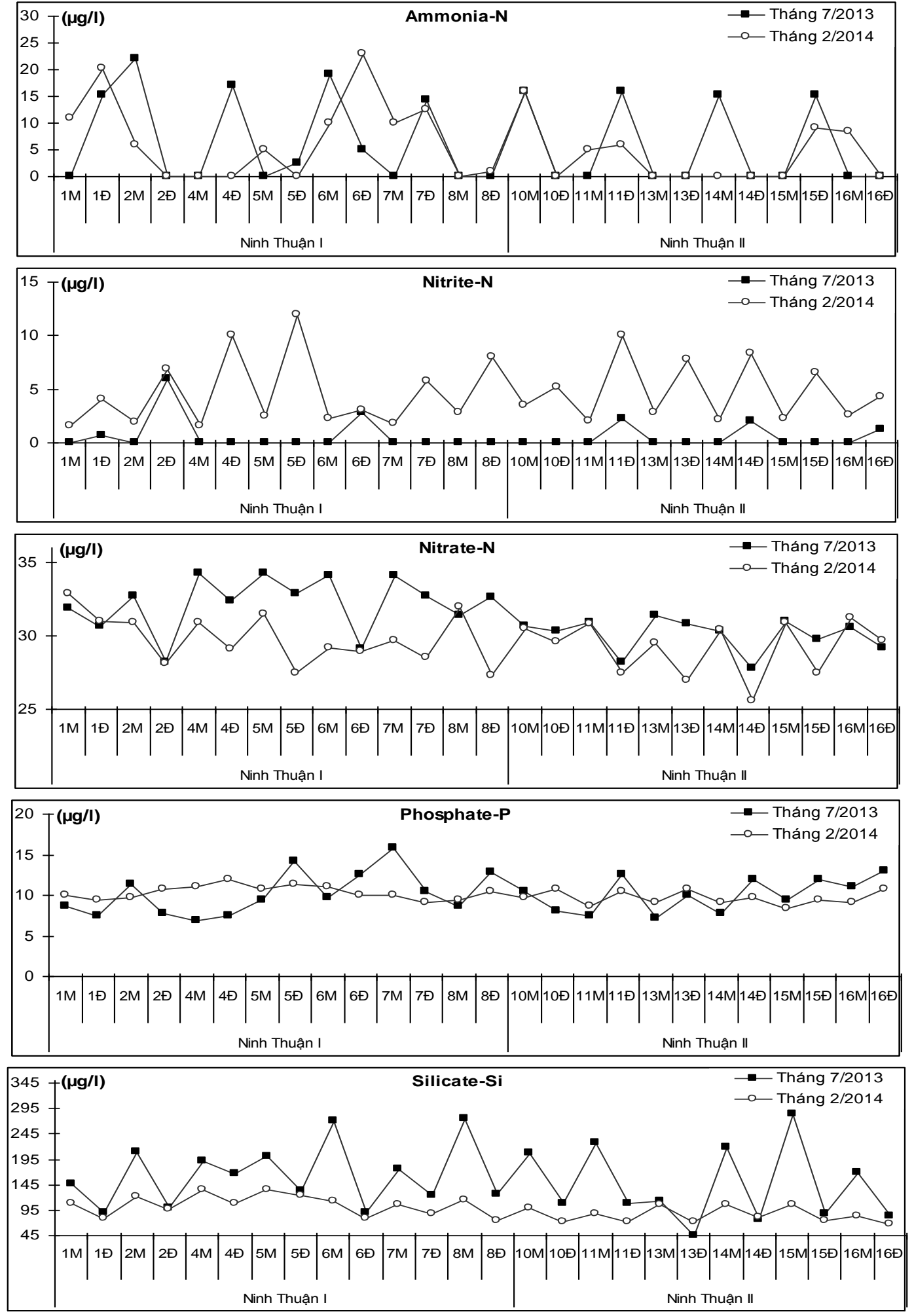

Hình 2. Phân bố hàm lượng của DO, TSS và các muối dinh dưỡng trong nước biển. 

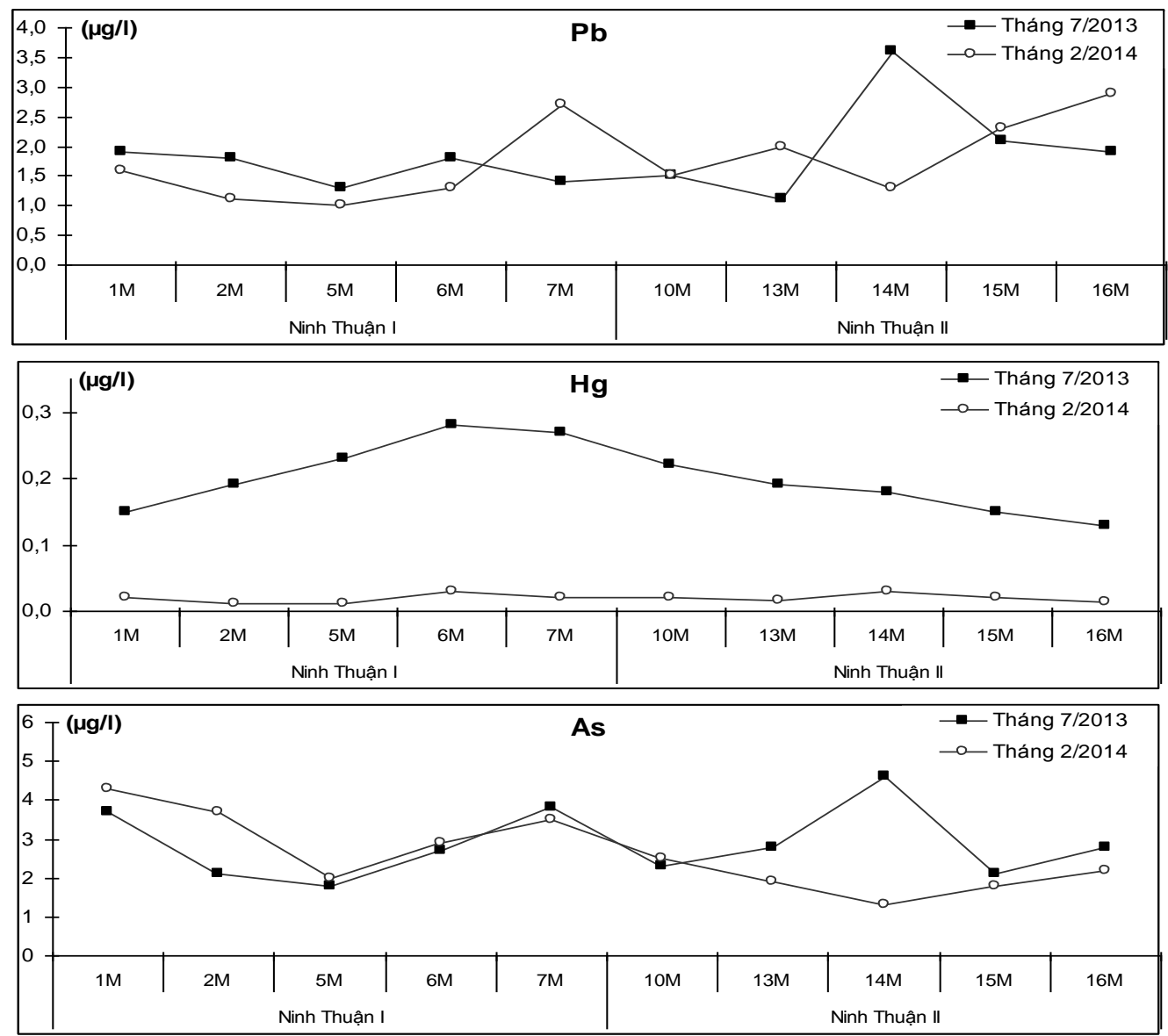

Hình 3. Phân bố hàm lượng của các kim loại nặng trong nước biển.

\subsection{Hiện trạng môi truờng trầm tích biển}

Dữ liệu từ bảng 3 và hình 4 cho thấy, Chc có hàm lượng tương đối thấp ở cả hai đợt khảo sát, phạm vi dao động vào tháng 7/2013 từ $0,06-0,73 \%$ (trung bình $0,25 \%$ ) và giá trị cao nhất ghi nhận được là $0,73 \%$ tại trạm $5(\mathrm{khu}$ vực ven bờ Ninh Phước). Vào tháng $2 / 2014$, Chc dao động trong khoảng từ $0,15-0,66 \%$ (trung bình $0,29 \%$ ). Hàm lượng của Nhc và $\mathrm{Pts}$ cũng có phạm vi dao động tương đối rộng ở cả hai đợt khảo sát. Ngoài ra, tất cả các yếu tố dinh dưỡng trong trầm tích (Chc, Nhc, Pts) ở khu vực ven bờ Ninh Phước cao hơn so với khu vực Ninh Hải trong cả hai đợt khảo sát.

Hàm lượng của Chc trong cả hai đợt khảo sát ít khác biệt. Tuy nhiên, hàm lượng của $\mathrm{Nhc}$ và Pts vào tháng 2/2014 thường cao hơn so với tháng 7/2013 (đặc biệt tại khu vực ven bờ Ninh Phước).

3.3. Đánh giá chất luợng môi truờng vùng nghiên cúu

\subsubsection{Môi trường nước biển ven bò̀}

Thống kê trong bảng 4 cho thấy, vùng nghiên cứu có mức dinh dưỡng thấp, các muối dinh dưỡng amoni và nitrit hầu như vắng mặt, trong khi đó hàm lượng các muốinitrat và phosphat luôn ở ngưỡng thấp. Đặc biệt, hàm lượng của TSS, các kim loại nặng trong nước biển $\mathrm{Pb}, \mathrm{Hg}$, As luôn ở mức rất thấp. Theo Quy chuẩn Kỹ thuật Quốc gia về nước biển ven bờ (QCVN 10:2015/BTNMT) qui định cho mục 
đích nuôi trồng thủy sản và bảo tồn thủy sinh cho thấy tất cả các muối dinh dưỡng amoni, nitrit, nitrat, phosphat đều có giá trị thấp hơn nhiều so với giá trị giới hạn $(\mathrm{GTGH})$. Hàm lượng của tất cả các kim loại nặng $\mathrm{Pb}, \mathrm{Hg}, \mathrm{As}$ đều có giá trị rất bé và luôn thấp hơn nhiều lần so với GTGH.

Bảng 3. Giá trị thống kê các yếu tố dinh dưỡng trong trầm tích biển

\begin{tabular}{lllll}
\hline \multirow{2}{*}{ Thời gian } & \multirow{2}{*}{ Giá trị } & Chc & Nhc & Pts \\
\cline { 3 - 5 } & & $(\%)$ & $(\mu \mathrm{g} / \mathrm{g})$ & $(\mu \mathrm{g} / \mathrm{g})$ \\
\hline \multirow{3}{*}{ Tháng 7/2013 } & TB & 0,25 & 342,03 & 198,29 \\
& LN & 0,73 & 665,80 & 380,08 \\
& BN & 0,06 & 115,20 & 55,80 \\
\multirow{2}{*}{ Tháng 2/2014 } & $\mathrm{n}$ & 10 & 10 & 10 \\
& TB & 0,29 & 614,58 & 407,31 \\
& LN & 0,66 & 975,30 & 660,50 \\
& BN & 0,15 & 472,50 & 295,50 \\
& $\mathrm{n}$ & 9 & 9 & 9 \\
\hline
\end{tabular}
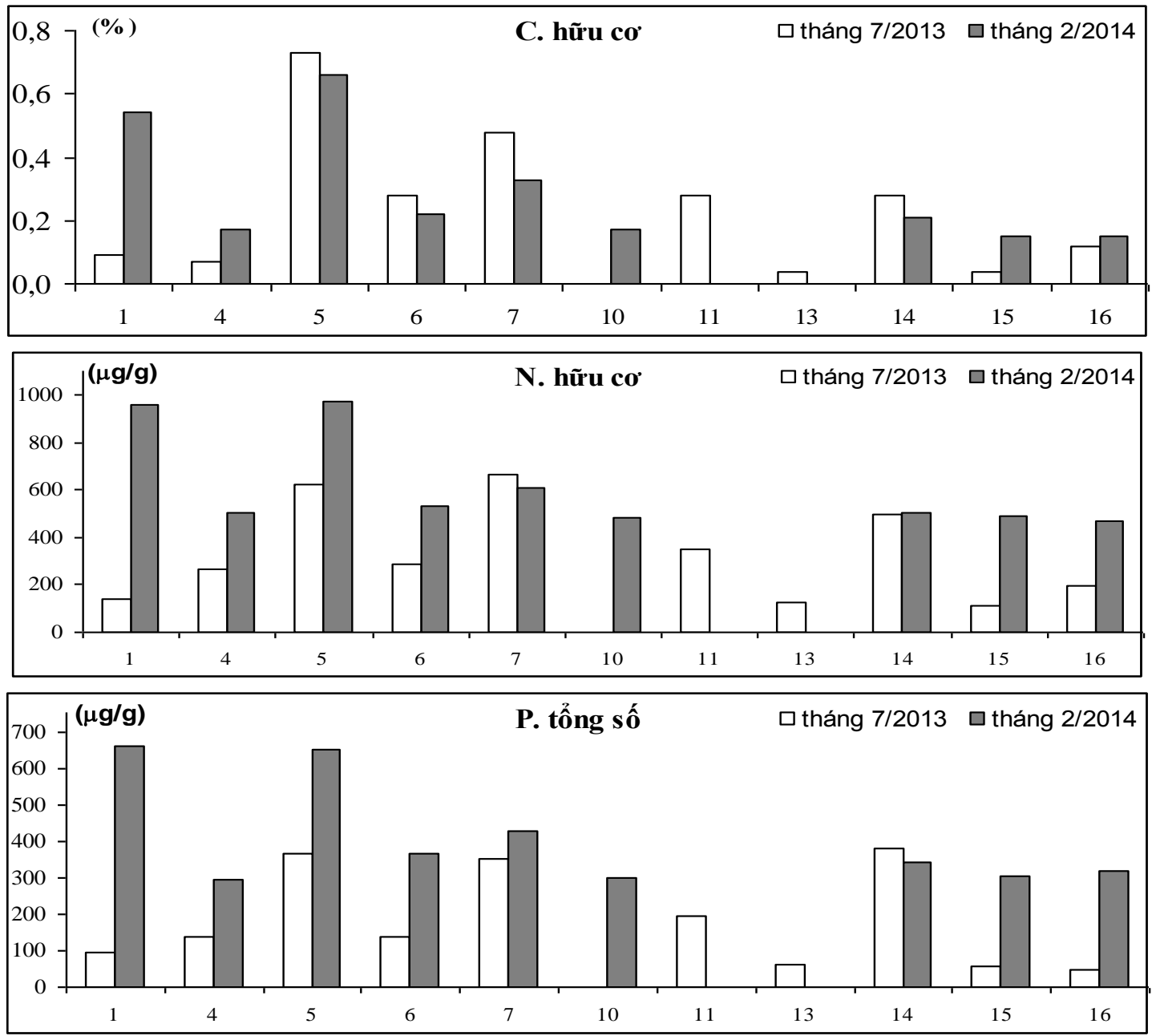

Hình 4. Phân bố hàm lượng của các yếu tố dinh dưỡng trong trầm tích biển. 
Bảng 4. Giá trị thống kê và hàm lượng trung bình của các thông số môi trường nước

\begin{tabular}{lllllllllll}
\hline \multirow{2}{*}{ Thời gian } & \multirow{2}{*}{ Giá trị } & $\mathrm{NH}_{3,4}-\mathrm{N}$ & $\mathrm{NO}_{2}-\mathrm{N}$ & $\mathrm{NO}_{3}-\mathrm{N}$ & $\mathrm{PO}_{4}-\mathrm{P}$ & $\mathrm{SiO}_{3}-\mathrm{Si}$ & $\mathrm{TSS}$ & $\mathrm{Pb}$ & $\mathrm{Hg}$ & $\mathrm{As}$ \\
\cline { 3 - 11 } & $(\mu \mathrm{g} / \mathrm{l})$ & $(\mu \mathrm{g} / \mathrm{l})$ & $(\mu \mathrm{g} / \mathrm{l})$ & $(\mu \mathrm{g} / \mathrm{l})$ & $(\mu \mathrm{g} / \mathrm{l})$ & $(\mathrm{mg} / \mathrm{l})$ & $(\mu \mathrm{g} / \mathrm{l})$ & $(\mu \mathrm{g} / \mathrm{l})$ & $(\mu \mathrm{g} / \mathrm{l})$ \\
\hline \multirow{4}{*}{ Tháng7/2013 } & $\mathrm{TB}$ & 6,1 & 0,6 & 31 & 10,2 & 155 & 3,0 & 1,84 & 0,20 & 2,87 \\
& $\mathrm{LN}$ & 22,0 & 6,0 & 34 & 15,8 & 285 & 9,9 & 3,60 & 0,28 & 4,60 \\
& $\mathrm{BN}$ & $\mathrm{KPH}$ & $\mathrm{KPH}$ & 28 & 6,8 & 46 & 1,0 & 1,10 & 0,13 & 1,80 \\
& $n$ & 26 & 26 & 26 & 26 & 26 & 26 & 26 & 26 & 26 \\
\multirow{4}{*}{ Tháng } & $\mathrm{TB}$ & 5,5 & 4,7 & 30 & 10,0 & 97 & 1,8 & 1,81 & 0,019 & 2,60 \\
& $\mathrm{LN}$ & 23,0 & 12,0 & 33 & 12,0 & 136 & 3,7 & 2,90 & 0,030 & 4,30 \\
& $\mathrm{BN}$ & $\mathrm{KPH}$ & 1,6 & 26 & 8,4 & 67 & 1,1 & 1,00 & 0,012 & 1,30 \\
& $n$ & 26 & 26 & 26 & 26 & 26 & 26 & 26 & 26 & 26 \\
\hline
\end{tabular}

QCVN 10:2015/BTNMT (cho vùng nuôi trồng thủy sản và bảo tồn thủy sinh)

$\begin{array}{llllllllll}\text { GTGH } & 100 & 55^{*} & 60 * & 200 & - & 50 & 50 & 1 & 20\end{array}$

Ghi chú:(*):Tiêu chuẩn chất lượng nước biển ven bờ của ASEAN; (-):Không qui định

3.3.2. So sánh chất lượng nước biển ven bò Ninh Thuận với các vùng biển ven bò̀ khác

So sánh chất lượng nước biển ven bờ Ninh Thuận qua hai chuyến khảo sát tháng 7/2013 và tháng 2/2014 với kết quả các chuyến khảo sát tại khu vực vịnh Nha Trang [9] và khu vực ven bờ Phú Yên [10] có thể thấy vùng nghiền cứu có hàm lượng TSS và muối silicat thấp hơn so với vịnh Nha Trang và vùng ven bờ Phú Yên, điều này nói lên rằng vùng biển ven bờ Ninh Thuận ít chịu sự ảnh hưởng của vật chất từ sông, suối. Mặt khác, hàm lượng các muối dinh dưỡng amoni, nitrit, nitrat và phosphattại vùng nghiên cứu cũng thấp hơn so với vịnh Nha Trang, nhưng lại cao hơn so với vùng ven bờ Phú Yên (Bảng 5).

Bảng 5. So sánh chất lượng nước vùng biển ven bờ Ninh Thuận với các vùng biển ven bờ lân cận

\begin{tabular}{llllllll}
\hline \multirow{2}{*}{$\begin{array}{l}\text { Địa điểm và } \\
\text { thời gian }\end{array}$} & $\begin{array}{l}\text { Giá } \\
\text { trị }\end{array}$ & $\mathrm{TSS}$ & $\mathrm{NH}_{3,4}-\mathrm{N}$ & $\mathrm{NO}_{2}-\mathrm{N}$ & $\mathrm{NO}_{3}-\mathrm{N}$ & $\mathrm{PO}_{4}-\mathrm{P}$ & $\mathrm{SiO}_{3}-\mathrm{Si}$ \\
\cline { 2 - 7 } & $\mathrm{mg} / \mathrm{l})$ & $(\mu \mathrm{g} / \mathrm{l})$ & $(\mu \mathrm{g} / \mathrm{l})$ & $(\mu \mathrm{g} / \mathrm{l})$ & $(\mu \mathrm{g} / \mathrm{l})$ & $(\mu \mathrm{g} / \mathrm{l})$ \\
\hline \multirow{2}{*}{$\begin{array}{l}\text { Vùng biển ven bờ } \\
\text { Phú Yên, 2010- }\end{array}$} & $\mathrm{BN}$ & 62,5 & $\mathrm{KPH}$ & $\mathrm{KPH}$ & 27 & 5,0 & 337 \\
2011 & $\mathrm{LN}$ & 72,3 & $\mathrm{KPH}$ & $\mathrm{KPH}$ & 23 & 3,0 & 182 \\
& $\mathrm{n}$ & 20 & $\mathrm{KPH}$ & $\mathrm{KPH}$ & 38 & 15,3 & 1500 \\
& $\mathrm{~TB}$ & 29,2 & 11,0 & 3,6 & 36 & 12,9 & 353 \\
Vùng biển vịnh & $\mathrm{BN}$ & 21,6 & 0,0 & 1,0 & 24 & 4,1 & 69 \\
Nha Trang, 2014 & $\mathrm{LN}$ & 53,0 & 108,0 & 4,5 & 80 & 27,8 & 3665 \\
& $\mathrm{n}$ & 36 & 36 & 36 & 36 & 36 & 36 \\
& $\mathrm{~TB}$ & 2,4 & 5,8 & 2,6 & 30 & 10,1 & 126 \\
Vùng biển ven bờ & $\mathrm{BN}$ & 1,0 & $\mathrm{KPH}$ & $\mathrm{KPH}$ & 26 & 6,8 & 46 \\
Ninh Thuận, 2013- & $\mathrm{LN}$ & 9,9 & 23,0 & 12,0 & 34 & 15,8 & 285 \\
2014 & $\mathrm{n}$ & 52 & 52 & 52 & 52 & 52 & 52 \\
\hline
\end{tabular}




\subsubsection{Môi truờng trầm tích biển}

Do Quy chuẩn Kĩ thuật Quốc gia về chất lượng trầm tích không qui định các giá trị giới hạn đối với yếu tố dinh dưỡng trong trầm tích, nề các tài liệu nước ngoài liên quan đến vấn đề này đã được tham khảo để đánh giá. Theo Hyland và cs (2000) trầm tích có dưới $0,05 \%$ và trên $3 \%$ chất hữu cơ sẽ làm giảm sự phong phú cũng như sinh khối của sinh vật đáy mềm [11], đối chiếu với trầm tích khu vực nghiên cứu với hàm lượng $\mathrm{C}$ hữu cơ dao động trong khoảng $0,06-0,73 \%$ (mùa khô) và $0,14-0,66 \%$ (mùa mưa) (Bảng 3) sẽ không gây ra những tác động tiêu cực đến môi trường trầm tích đáy vùng nghiên cứu. Những giá trị này đồng thời cũng thấp hơn GTGH $2 \%$ được quy định trong tiêu chuẩn của Trung Quốc về hàm lượng $\mathrm{C}$ hữu cơ trong trầm tích với mục đích bảo vệ đời sống thủy sinh [12]. Quá trình khoáng hóa các chât hữu cơ chứa $\mathrm{N}$ trong trầm tích không khác nhau trong điều kiện hiếu khí và yếm khí, trong lúc đó các hợp chất chứa $\mathrm{P}$ rất bền vững trong môi trường ôxy hóa và các yếu tố này bị khoáng hóa đáng kể trong tình trạng thiếu ôxy hòa tan [13]. Tuy nhiên những khảo sát trên đã cho thấy, thủy vực nghiên cứu có hàm lượng ôxy hòa tan rất phong phú (luôn $>5 \mathrm{mg} / \mathrm{l}$ ), như vậy khả năng khoáng hóa của các yếu tố nói trên là rất thấp.

\section{4. Đặc điểm các muối dinh duỡng}

Tỉ số phân tử nitrat/phosphat dao động trong phạm vi tương đối hẹp trong cả hai đợt khảo sát $(4,78-11,17$; trung bình 7,19 vào tháng $7 / 2013$ và $5,37-8,15$; trung bình 6,59 vào tháng $2 / 2014)$. Như vậy giá trị trung bình của tỉ số phân tử nitrat/phosphat luôn luôn bé hơn chỉ số Redfield [14], chủ yếu do hàm lượng phosphat trong thủy vực nghiên cứu tăng (hàm lượng nitrat thường ít thay đổi), điều đó có nghĩa muối dinh dưỡng nitrat luôn đóng vai trò của yếu tố dinh dưỡng giới hạn (limiting nutrient) trong cả hai đợt khảo sát tại thủy vực ven bờ Ninh Thuận. Ngoài ra, tỉ số phân tử N/Si luôn nhỏ hơn 1 rất nhiều trong cả hai đợt khảo sát, điều đó chứng tỏ không có sự thiếu hụt của Si so với với $\mathrm{N}$ tại vùng nghiên cứu.

\section{Kết luận}

Các dẫn liệu cho thấy chất lượng môi trường nước tại hai khu vực ở cả hai đợt khảo sát còn rất tốt về mặt sinh thái, mức tích lũy ôxy hòa tan của thủy vực nghiên cứu khá cao (luôn $>5 \mathrm{mg} / \mathrm{l})$, chưa có hiện tượng ưu dưỡng hóa. Nhìn chung, hàm lượng của TSS, các muối dinh dưỡng amoni, nitrit, nitrat, phosphat và đặc biệt là các kim loại nặng đều thấp hơn rất nhiều so với GTGH. Chất lượng môi trường nước ở hai khu vực khảo sát tương đối đồng nhất, ít chịu ảnh hưởng nguồn nước ngọt từ sông suối. Muối dinh dưỡng nitrat luôn luôn đóng vai trò của yếu tố dinh dưỡng giới hạn tại thủy vực nghiên cứu ở cả hai đợt khảo sát.

Chất lượng môi trường trầm tích tại hai khu vực còn khá tốt. Hàm lượng của các yếu tố dinh dưỡng trong trầm tích không cao, đặc biệt hàm lượng Chc rất thấp. Chất lượng môi trường trầm tích tại khu vực ven bờ Ninh Hải tốt hơn so với khu vực Ninh Phước. Hàm lượng Nhc và Pts trong trầm tích thường cao hơn vào tháng 2/2014.

\section{Lời cảm ơn}

Tác giả chân thành cảm ơn chủ nhiệm đề tài "Điều tra hệ sinh thái biển điển hình tại khu vực ven bờ Ninh Thuận" cho phép sử dụng số liệu.

\section{Tài liệu tham khảo}

[1] Võ Văn Lành, Các công trình về vùng trồi mạnh Nam Trung bộ, NXB Khoa học Kỹ thuật, Hà Nội, 1995.

[2] Nguyễn Văn Long và cộng sự, "Xây dựng chương trình giám sát định kỳ rạn san hô tại Ninh Thuận”, Báo cáo tổng kết, Viện Hải dương học, 2011.

[3] Sở Tài nguyên và Môi trường tỉnh Ninh Thuận, Kết quả quan trắc chất lượng nước biển ven bờ tại các càng cá, khu du lịch và nuôi trồng thủy sản (đợt 2), Báo cáo tổng kết, 2017.

[4] Đào Mạnh Tiến, Điều tra địa chất, khoáng sản, địa chất môi trường và tai biến địa chất vùng biển Nam Trung Bộ tỷ lệ $1 / 100.000$ và một số vùng trọng điểm tỷ lệ 1/50.000", 2001 - 2006. 
[5] A. Rice, B. Baird, D. Eaton, Standard Methods for the Examination of Water and Wastewater, 22 ${ }^{\text {nd }}$ Edition, American Public Health Association, Washington D.C, 2012.

[6] FAO, Manual of Methods in Aquatic Environment Research - Part2: Methods for Detection, Measurement and Monitoring of water polution, 1975.

[7] Bộ Tài nguyên và Môi trường, Quy chuẩn Kỹ thuật Quốc gia về chất lượng môi trường nước biển, QCVN 10-MT: 2015/BTNMT, Hà Nội, 2015.

[8] Australian Government, ASEAN Marine Water Quality Management Guidelines and Monitoring Manual. Asean Marine Water Quality Criteria, 2008.

[9] Lê Thị Vinh, Báo cáo giám sát môi trường khu bảo tồn biển Hòn Mun, vịnh Nha Trang, Ban quản lý khu bảo tồn biển vịnh Nha Trang, 2014.
[10] Lê Thị Vinh, Chất lượng nước biển ven bờ Phú Yên (2010-2011), Báo cáo chuyên đề trong khuôn khổ đề tài "Điều tra, đánh giá thực trạng hệ sinh thái rạn san hô vùng ven biển tỉnh Phú Yên", 2011.

[11] J. Hyland, I. Karakassis, P. Magni, A. Petrov, J. Shine, Summary Report: Results of initial planning meeting of the United Nations Educational, Scientific and Cultural Organization (UNESCO) Benthic Indicator Group, 2000.

[12] CCME, Canadian Environmental Quality Guidelines, 2003.

[13] S. H. Lars, H. B. Thomas, Aerobic and anaerobic mineralization of organic material in marine sediment microcosms, Marine Ecology progress series, 75 (1991) 283-291.

[14] A.C. Redfield, The Biological control of chemical factors in the environment. Am. Sci. 46 (1958) 205-222. 